\title{
EVALUATION OF THE AEROSOL TYPE EFFECT ON THE SURFACE REFLECTANCE RETRIEVAL USING CHRIS/PROBA IMAGES OVER LAND
}

\author{
C. Tirelli ${ }^{\mathrm{a},}$ *, C.Manzo ${ }^{\mathrm{b}}$, G. Curci $^{\mathrm{a}}$, C. Bassani ${ }^{\mathrm{b}}$ \\ a University of L'Aquila, CETEMPS, Department of Physical and Chemical Sciences, L'Aquila, Italy \\ - cecilia.tirelli@aquila.infn.it, gabriele.curci@aquila.infn.it \\ b Institute for Atmospheric Pollution Research (IIA), Italian National Research Council (CNR), Research Area of Rome 1, Via \\ Salaria km 29,300, 00015 Monterotondo Scalo, Rome, Italy.-c.manzo@iia.cnr.it, cristiana.bassani@iia.cnr.it
}

KEY WORDS: Atmospheric correction, Aerosols, Surface Reflectance, CHRIS/PROBA, Hyperspectral, FlexAOD.

\begin{abstract}
:
Surface reflectance has a central role in the analysis of land surface for a broad variety of agricultural, geological and urban studies. An accurate atmospheric correction, obtained by an appropriate selection of aerosol type and loading, is the first requirement for a reliable surface reflectance estimation. The aerosol type is defined by its micro-physical properties, while the aerosol loading is described by optical thickness at $550 \mathrm{~nm}$. The aim of this work is to evaluate the radiative impact of the aerosol model on the surface reflectance obtained from CHRIS (Compact High Resolution Imaging Spectrometer) hyperspectral data over land by using the specifically developed algorithm CHRIS@CRI (CHRIS Atmospherically Corrected Reflectance Imagery) based on the 6SV radiative transfer model. Five different aerosol models have been used: one provided by the AERONET inversion products (used as reference), three standard aerosol models in 6SV, and one obtained from the output of the GEOS-Chem global chemistry-transport model (CTM). As test case the urban site of Bruxelles and the suburban area of Rome Tor Vergata have been considered. The results obtained encourages the use of CTM in operational retrieval and provides an evaluation of the role of the aerosol model in the atmospheric correction process, considering the different microphysical properties impact.
\end{abstract}

\section{INTRODUCTION}

\subsection{Introduction}

Hyperspectral remote sensing is used in a wide variety of topics for atmospheric, climatological, environmental and land surface applications (Paronis et al., 2010). To obtain reliable estimations of surface reflectance from satellite, the images acquired must be corrected considering the aerosol particles effects on the spectrum recorded. The atmospheric correction algorithms for land have evolved over the years, from earlier scene-based empirical approches (Kruse et al., 1985; Roberts et al., 1986; Conel et al., 1987) to more recent methods based on rigorous radiative transfer modeling (Gao et al, 1993; Ritcher et al., 1996). The combined use of model and empirical procedures have been proposed in few papers (Ben-Dor, 2004). An accurate atmospheric correction is obtained by an appropriate selection of aerosol loading and type used in the algorithm designed. Several studies have shown the crucial role of aerosol optical thickness at $550 \mathrm{~nm}$ in the atmospheric transfer modeling (Kauffman et al., 1997; Kokhanovsky et al., 2007, 2008, 2010, Bassani et al., 2010) and on the atmospheric correction of multi and hyperspectral data for ocean and land properties retrieval (Kotchenova et al., 2008; Vermote et al, 1997b; Kauffman et al., 2002; Gaunter et al., 2007; Gao et al., 2009; Goetz et al, 1985). In this work, the aerosol radiative impact was investigated comparing the reflectance obtained by applying the CHRIS@CRI algorithm with different aerosol models: one using AERONET data, three standard types implemented in $6 \mathrm{SV}$, and one extracted from the detailed simulations of the chemistry-transport model GEOS-Chem. The microphysical properties (size distribution, real and imaginary part of the refractive index), and the optical properties (single scattering albedo and asymmetry parameter) from sunphotometer data are considered as reference.

\section{DATA}

\subsection{AERONET data}

The automatic tracking sunphotometer CIMEL CE-318 measures the direct spectral solar irradiance and sky radiance for solar almucantar or principal plane scenario at six normal bands (440, 500, 670, 870, 940, and $1020 \mathrm{~nm}$ ) (Holben et al., 1998). It provides the aerosol optical thickness at the six nominal bands, the columnar content of water vapor (wv) and ozone $\left(\mathrm{O}_{3}\right)$ from the direct component of the solar irradiance. The aerosol micro-physical and optical properties (aerosol complex refractive index, single scattering albedo and the scattering phase function) are retrieved from the diffuse components of sky radiance on four bands $(442,668,870$, and $1020 \mathrm{~nm}$ ) at specific angles (Dubovik et al., 2000). Aerosol optical depth data and inversions products are provided for three data quality levels: Level 1.0 (unscreened), Level 1.5 (cloud-screened), and Level 2.0 (cloud-screened and qualityassured). The AERONET inversion products are often available only at quality Level 1.5, Level 2.0 data were preferred when possible for the atmospheric correction process.

\subsection{CHRIS data}

CHRIS (Compact High Resolution Imaging Spectrometer) on PROBA satellite is an high resolution multiangular imaging spectrometer. CHRIS provides acquisitions up to 62 narrow and quasi contiguous spectral bands, with a spectral range from 400 to $1050 \mathrm{~nm}$ and a spatial resolution of 17 or $34 \mathrm{~m}$. The specific feature of CHRIS is that it provides data from five observation angles during the same overpass. In this work all CHRIS images in this work are acquired in Mode 3, characterized by a full resolution and a full swath. The specific requirements for imagery acquisition were the clear-sky condition, and high solar irradiation (solar zenith angle $<60^{\circ}$ ) and the aerosol loading defined by an AOT value $>0.1$. 


\begin{tabular}{|c|c|c|}
\hline & $\begin{array}{c}\text { Tor Vergata } \\
\text { Rome }\end{array}$ & Bruxelles \\
\hline Date & $01 / 03 / 2005$ & $19 / 08 / 2009$ \\
\hline Time AERONET & $10.31($ Level 2) & $9.48($ Level 1.5) \\
\hline Time CHRIS & 10.33 & 9.51 \\
\hline $\begin{array}{c}\text { AOT @ 550nm } \\
\text { AERONET }\end{array}$ & 0.117 & 0.122 \\
\hline $\begin{array}{c}\text { AOT@ 550nm } \\
\text { GEOS-Chem }\end{array}$ & 0.098 & 0.133 \\
\hline $\mathrm{O}_{3} \mathrm{gm}^{-2}$ & 0.390 & 0.314 \\
\hline $\mathrm{Wv} \mathrm{gm}^{-2}$ & 0.352 & 2.598 \\
\hline Zenith angle $\left(^{\circ}\right)$ & 50 & 45 \\
\hline
\end{tabular}

Table 1. Date and time of the two selected CHRIS images over Tor Vergata (Rome) and Bruxelles and of the nearly simultaneous AERONET stations acquisitions. The corresponding values of the solar zenith angle, the aerosol optical thickness at $550 \mathrm{~nm}$ (AOT@550nm) from AERONET data and from GEOS-Chem simulations, the water vapour (wv) and ozone (O3) columns, and the quality Level of AERONET data are also shown.

Table 1 shows date and time of selected CHRIS images and of the corresponding atmospheric aerosol data (AOT@550nm,wv and $\mathrm{O}_{3}$ columnar contents) from simultaneous AERONET measurements. The value of AOT@550nm obtained from GEOS-Chem model simulations, the solar zenith angle relative to the two CHRIS overpasses and the AERONET data quality Levels is also specified for each case studies.

\section{METHODS}

\subsection{Atmospheric correction algorithm}

The physically-based atmospheric correction algorithm CHRIS@CRI needs as input the aerosol AOD at $550 \mathrm{~nm}$, the water vapor (wv) and ozone columnar content (O3) and a standard or user-defined aerosol type, defined by its size distribution function and complex refractive index. The algorithm for the atmospheric correction of CHRIS images was implemented following the method developed by Bassani et al., 2010. The surface reflectance $\rho_{\mathrm{g}}$, is computed, for each instrument channels as:

$\rho_{g}=\frac{t_{g} \rho_{a t m}-\rho_{T O A}}{S\left(t_{g} \rho_{a t m}-\rho_{T O A}\right)-t_{g} t_{g}}$

where $\rho_{T O A}=$ top of atmosphere $(\mathrm{TOA})$ reflectance

$\rho_{\mathrm{atm}}=$ the atmospheric reflectance (or path radiance)

$\mathrm{S}=$ spherical albedo

$\mathrm{t}_{\mathrm{g}}=$ the gas transmittance

$\mathrm{t}_{\mathrm{s}}=$ the total transmittance

The radiative quantities are simulated by a pixel-by-pixel method over a scan-line with a spectral sampling of $2.5 \mathrm{~nm}$ covering the domain from $350 \mathrm{~nm}$ to $2.5 \mu \mathrm{m}$ by using the latest version of $6 \mathrm{SV}$. To avoid a considerable computational processing time, due to the pixel-by-pixel method, the 6SV code runs just for the viewing geometry on a selected number of pixels, equidistant along a scan line. The radiative quantities are then interpolated along all of the scan line pixels. The
CHRIS@CRI algorithm computes the convolution of radiative quantities on the spectral response of CHRIS sensor assumed Gaussian. The central wavelengths and the FWHM are provided by the HDF file, containing the CHRIS image. The HDF file provides also the geometric input, as well as the longitude (degrees) and latitude (degrees) for each CHRIS image pixel. In the atmospheric correction of satellite data in the visible and near-infrared channels, it is necessary to remove the adjacency effect due to the reflection from neighbors pixels. The surface reflectance is calculated applying the empirical formula used in atmospheric correction algorithms (Bassani et al., 2010; Kotchenova et al., 2008; Vermote et al., 1997b)

$$
\rho(\lambda)=\rho_{g+} \frac{t_{\text {dif }}^{u}}{-\frac{\tau(\lambda)}{\mu_{V}}}\left[\rho_{g}-<\rho_{g}>\right]
$$

where $\left\langle\rho_{\mathrm{g}}\right\rangle$ is the mean of the pixels adjacent to the viewing pixel covering CHRIS sensors swath $\left(13 \mathrm{~km}^{2}\right)$.

With the aim to evaluate the role of the aerosol model in the atmospheric correction procedure, the micro-physical properties of the 6SV aerosol standard types (maritime, urban or continental), those obtained from AERONET inversion products, and from the GEOS-Chem model simulations, have been introduced in the CHRIS@CRI algorithm. The 6SV standard types (maritime, urban, continental) are defined as a combination of the four basic aerosol components: sea-salt, water-soluble, dust-like and soot (see Table 2).

\begin{tabular}{|l|c|c|c|c|}
\hline & $\begin{array}{c}\text { dust- } \\
\text { like }\end{array}$ & oceanic & $\begin{array}{c}\text { water- } \\
\text { soluble }\end{array}$ & soot \\
\hline urban & 0.17 & 0 & 0.61 & 0.22 \\
\hline maritime & 0 & 0.95 & 0.05 & 0 \\
\hline continental & 0.70 & 0 & 0.29 & 0.01 \\
\hline
\end{tabular}

Table 2. The volumetric mixing ratio of the four basic components (dust-like, oceanic, water-soluble and soot) for urban, maritime and continental 6SV standard aerosol models

(D’Almeida et al.,1991; Kokhanovsky et al., 2008)

\subsection{GEOS-Chem/FlexAOD model}

GEOS-Chem is a global chemistry-transport model (CTM) (Bey, 2001) for atmospheric composition driven by assimilated meteorology from the Goddard Earth Observing System (GEOS) of the NASA Global Modeling and Assimilation Office (GMAO). Here we use model version 9-01-03, which is freely available online together with full documentation at http://geoschem.org. Meteorological data version are GEOS-5 at a spatial resolution of $2^{\circ} \times 2.5^{\circ}$ in the horizontal and 47 layers in the vertical (from the surface to $0.01 \mathrm{hPa}$ ), with resolution degrading from $\sim 100 \mathrm{~m}$ in the first kilometer, to $\sim 500 \mathrm{~m}$ in the upper troposphere, and a few $\mathrm{km}$ in the mesosphere. 


\section{RESULTS}

\subsection{Aerosol microphysical and optical properties} comparison.

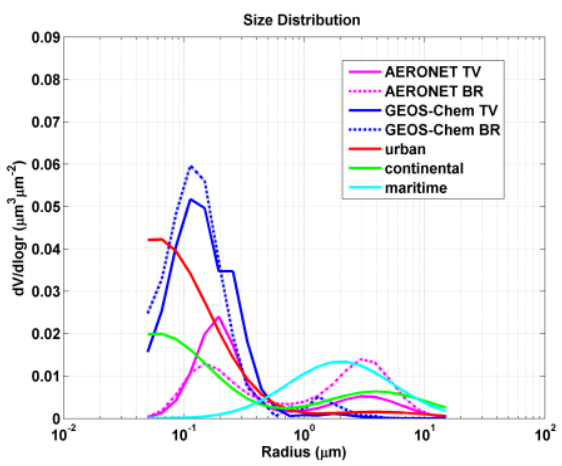

Figure 1. Aerosol volume size distributions from urban (red), continental (green) and maritime (cyan) 6SV aerosol standard types, AERONET data (magenta), and GEOS-Chem model (blue) corresponding to CHRIS image of $1^{\text {st }}$ May 2005 (dashedline) over Tor Vergata (TV) and of $19^{\text {th }}$ August 2009 (solid line) over Bruxelles (BR).

In Figure 1 the comparison of the aerosol volume size distributions is shown. The AERONET size distribution does not show a clear prevalence of fine or coarse mode, while for the GEOS-Chem model the distribution is mostly shifted to the fine mode, with a peak concentration higher of a factor of 3 with respect to AERONET. The 6SV urban and continental fine modes are similar, but the urban one shows a doubled peak concentration. The $6 \mathrm{SV}$ maritime model does not have a fine mode and the coarse mode is similar to that from Bruxelles AERONET.
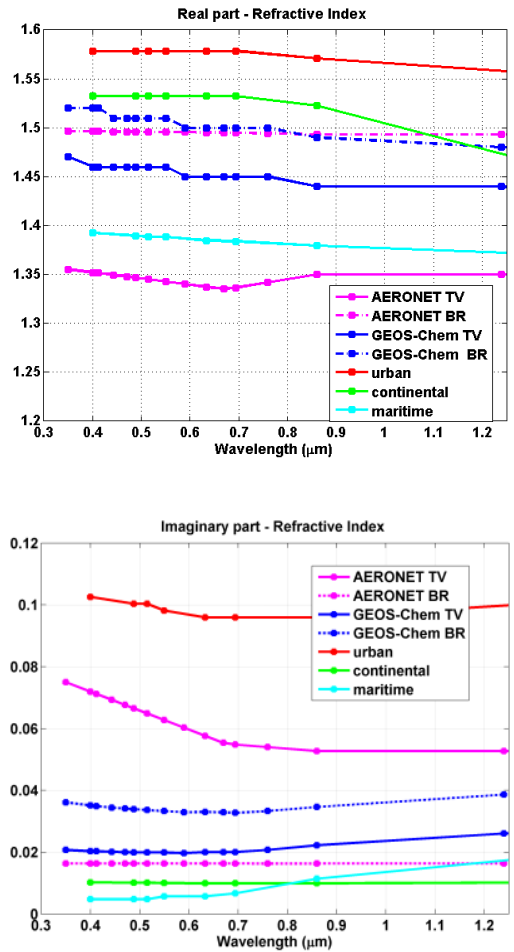

Figure 2. Real (top) and imaginary (bottom) part of the refractive index obtained from urban (red), continental (green) and maritime (cyan) 6SV aerosol standard types, AERONET data (magenta) and GEOS-Chem model (blue) corresponding to CHRIS image of $1^{\text {st }}$ May 2005 (dashed-line) over Tor Vergata (TV) and of $19^{\text {th }}$ August 2009 (solid line) over Bruxelles (BR).

In Figure 2 the analysis of the refractive index is presented.

The refractive index real parts are similar for the two GEOSChem scenes, the AERONET data of Bruxelles and the 6SV continental mode with values around 1.45-1.50. Tor Vergata AERONET values are lower and similar to the urban mode, with values near 1.35 .

For the imaginary part, the $6 \mathrm{SV}$ continental and maritime values are in the same range of Bruxelles AERONET data and Tor Vergata GEOS-Chem ones, near or lower 0.02. While Bruxelles GEOS-Chem data are higher. The Tor Vergata sunphotomer data displays values higher than 0.5 , typical of an absorbing aerosol type. Finally, the urban mode shows the higher values, near 0.1 .

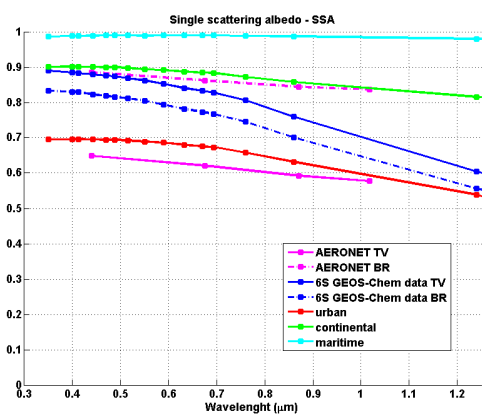

Figure 3. Single scattering albedo (SSA) retrieved from AERONET and simulated with 6SV using microphysical properties from the five models.

In Figure 3 the single scattering albedo behavior is shown for the five aerosol types, for the two scenes. The AERONET data for Rome describe an absorbing aerosol type, with values near 0.6 , similar to those of the urban aerosol. While Bruxelles AERONET values are nearly superimposed to those of the continental 6SV standard type, near 0.9. The GEOS-Chem single scattering albedo values are similar for both Tor Vergata and Bruxelles, nera 0.8 and 0.9 until 750 and $600 \mathrm{~nm}$, respectively and decreasing to 0.6 for higher wavelengths.

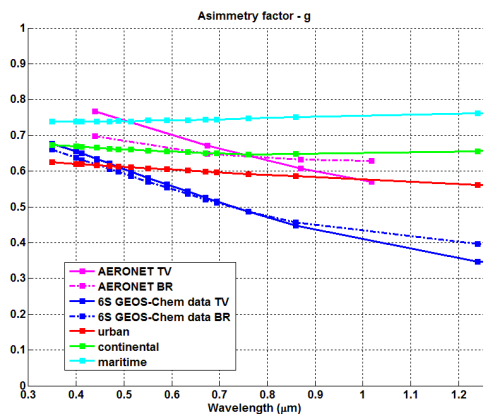

Figure 4. Asymmetry factor $(\mathrm{g})$ retrieved from AERONET and simulated with $6 \mathrm{SV}$ using microphysical properties from the five models. 
In Figure 4 the asymmetry parameter values are presented for the two scenes, for the different aerosol models.

The two AERONET curves display values near 0.75-0.7 (440 $\mathrm{nm})$ decreasing to $0.6(1 \mathrm{~mm})$. The GEOS-Chem values are lower with respect to AERONET and vary from 0.65 to 0.4 , in both scenes, reflecting an enhanced presence of fine particles with respect to AERONET. The g values of continental aerosol are near 0.65 while the urban and the maritime aerosols have spectrally constant values of g, near 0.6 and 0.75 , respectively, and the latter reflecting the prevalence of coarse particles in its size distribution

\subsubsection{CHRIS@CRI algorithm validation and reflectance spectral behavior.}

To validate the atmospheric correction algorithm CHRIS@CRI, the reflectance values obtained using the reference tool BEAM, were compared to those obtained by applying the CHRIS@CRI algorithm using AERONET data for aerosol loading and aerosol microphysical properties for the Bruxelles image. The percentage difference:

$$
\Delta \rho_{A B}=\left(\frac{\rho_{\text {AERONET }}-\rho_{\text {BEAM }}}{\rho_{\text {BEAM }}}\right) \times 100
$$

was calculated for all spectral channels to evaluate and quantify the comparison between the reflectance values.

In Table 3 the results for the percentage difference analysis are resumed for all CHRIS channels, considering the mean value and the relative standard deviation. For only three channels the mean value is higher than $10 \%$, those centred at $443 \mathrm{~nm}, 570$ $\mathrm{nm}$ and $897 \mathrm{~nm}$. In particular, the results for the latter are probably due to some miscalibration trends that characterized CHRIS sensor (Guanter et al., 2005).

\begin{tabular}{|l|c|c|}
\hline & $\begin{array}{c}\text { Mean \% } \\
\text { reflectance } \\
\text { difference }\end{array}$ & $\begin{array}{c}\text { Standard } \\
\text { deviation }\end{array}$ \\
\hline Band 1 & -15.3 & 24.1 \\
\hline Band 2 & 8.7 & 8.6 \\
\hline Band 3 & 4.7 & 4.9 \\
\hline Band 4 & 7.9 & 3.7 \\
\hline Band 5 & 14.4 & 4.9 \\
\hline Band 6 & 8.8 & 5.2 \\
\hline Band 7 & 0.5 & 7.2 \\
\hline Band 8 & -2.5 & 7.9 \\
\hline Band 9 & 6.1 & 3.3 \\
\hline Band 10 & -4.1 & 2.4 \\
\hline Band 11 & -0.05 & 1.7 \\
\hline Band 12 & 2.5 & 1.3 \\
\hline Band 13 & 1.03 & 1.1 \\
\hline Band 14 & -4.7 & 1.3 \\
\hline Band 15 & -2.8 & 0.9 \\
\hline Band 16 & -24.0 & 1.5 \\
\hline Band 17 & 5.8 & 2.5 \\
\hline Band 18 & -6.2 & 0.7 \\
\hline
\end{tabular}

Table 3. Mean and standard deviation of the relative differences of reflectance, for all instrumental channels, obtained with AERONET model with respect to those obtained with the tool BEAM, for the CHRIS image over Bruxelles.
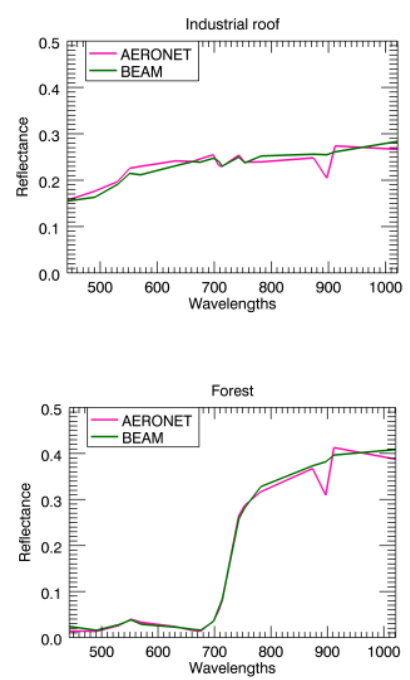

Figure 5. The surface reflectance obtained using the BEAM tool and applying the CHRIS@CRI algorithm using AERONET data for two different targets, an industrial roof (top) and a vegetated area (bottom).

In 5 the surface reflectance obtained using the BEAM tool and applying the CHRIS@CRI algorithm using AERONET data are presented as a function of wavelength for the Bruxelles image. The two reflectance curves show the typical behavior expected for a vegetated area and for a brighter target, as an industrial roof. For the first, the reflectance values are lower than 0.1 from 400 to $700 \mathrm{~nm}$, while in the NIR channels they are higher than 0.3 . For the brighter target they vary similarly between 0.15 to 0.3 . The reflectance spectral behaviour obtained with the two methods is in perfect agreement with the results of the surface reflectance percentage difference $\left(\Delta \rho_{A B}\right)$ analysis.

\subsubsection{Reflectance analysis.}

The aerosol radiative impact has been quantitatively investigated comparing the reflectance obtained by applying the CHRIS@CRI algorithm with the five different aerosol models. In particular, the attention of our work was centered on the GEOS-Chem results. The aerosol loading is described by the aerosol optical depth at 550nm from AERONET data for all cases except GEOS-Chem. In this case the simulated value is directly used. The relative difference with its corresponding reflectance is used as metric to evaluate the differences among models:

$$
\Delta \rho_{(C, U M, f)}=\left(\frac{\rho_{(c u m, f)}-p_{\text {AERONET }}}{\rho_{\text {AERONET }}}\right) \times 100
$$

The aerosol model defined by AERONET data is used as reference. In Table 4 the mean and standard deviation of the differences in all pixels are reported. For Tor Vergata CHRIS image, the best agreement is achieved with the urban model (near -1\%) while for Bruxelles image the GEOS-Chem model shows the lower percentage reflectance difference (near $0 \%$ ). The GEOS-Chem results for Tor Vergata show values near $10 \%$, similar to those obtained for the continental mode. This thus lends confidence in the use of the GEOS-Chem transport 
model to simulate aerosol properties. The results obtained for the reflectance values after the atmospheric correction with the CHRIS@CRI algorithm by using the different aerosol types are in agreement with the analysis of the five aerosol model microphysical and optical properties.

\begin{tabular}{|c|c|c|}
\hline & $\begin{array}{c}\text { Tor Vergata } \\
\% \text { Reflectance } \\
\text { difference }\end{array}$ & $\begin{array}{c}\text { Bruxelles } \\
\text { \%Reflectance } \\
\text { difference }\end{array}$ \\
\hline Continental & $-11 \pm 2.7$ & $1.4 \pm 1.0$ \\
\hline Urban & $-1.3 \pm 0.5$ & $7.7 \pm 3.1$ \\
\hline Maritime & $-6.7 \pm 1.8$ & $-5.00 \pm 3.4$ \\
\hline GEOS-Chem & $-10 \pm 2.4$ & $0.31 \pm 1.3$ \\
\hline
\end{tabular}

Table 4. Mean and standard deviation of the relative differences of reflectances obtained with different aerosol models (continental, urban, maritime, and GEOS-Chem) with respect to those obtained with the AERONET model, for the two CHRIS images.

In Figure 6 the relative difference of the surface reflectance at $550 \mathrm{~nm}$ of the values obtained from the CHRIS@CRI atmospheric correction algorithm with the GEOS-Chem model and those obtained with AERONET data, are shown for both Tor Vergata and Bruxelles. The values are in agreement with the results showed in the Table 4 and display no notable systematic bias.
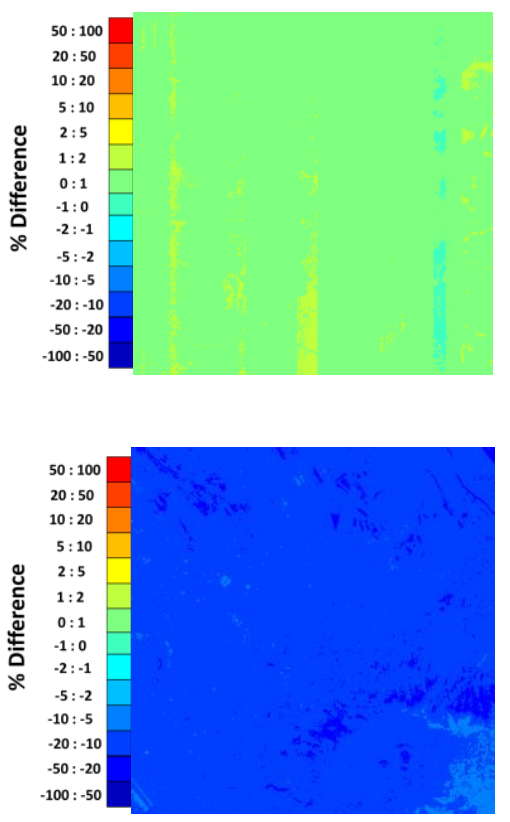

Figure 6. Relative difference at $550 \mathrm{~nm}$ of the surface reflectance values obtained from the CHRIS@CRI atmospheric correction algorithm with GEOS-Chem model and those obtained with AERONET data, used as reference. The results are shown for CHRIS images over Tor Vergata (top) and Bruxelles (bottom).

\section{CONCLUSIONS}

The CHRIS@CRI atmospheric correction algorithm was applied to two CHRIS-PROBA hyperspectral images over land (Tor Vergata on $1^{\text {st }}$ March 2005 , Bruxelles on $19^{\text {th }}$ August 2009). The algorithm was instructed with five alternative aerosol models (one obtained from AERONET inversion products, three from $6 \mathrm{SV}$ radiative transfer model standard types, and one simulated with the chemistry-transport model GEOS-Chem) to evaluate their impact on the surface reflectance retrieval. The reflectance derived from AERONET was chosen as reference. The general quality of the CHRIS@CRI algorithm was benchmarked against results obtained with the standard BEAM software on the Bruxelles image. The comparison of CHRIS@CRI results are found to be consistent with BEAM reflectance within $10 \%$ for all wavelengths, without any notable systematic bias. This thus lends confidence in the use of the CHRIS@CRI algorithm.

The analysis of the relative differences between the surface reflectance calculated with the different aerosol models displays results in agreement with the microphysical and optical properties of the aerosol models. The AERONET data have aerosol properties mostly similar to a urban and a continental standard type, for Tor Vergata and Bruxelles, respectively. The aerosol properties from the GEOS-Chem model are similar to a continental standard type in both scenes. For these test cases, the role of the real and imaginary part of refractive index was shown to be more relevant to determine the aerosol model radiative behavior rather than the size distribution function.

This work provides an evaluation of the role of the aerosol model in the atmospheric correction process, considering the different microphysical properties impact. This work also showed that the use of output from chemistry-transport models (CTM) , may be fruitfully used in satellite retrieval algorithms. In fact, it was demonstrate that CTMs are able to well reproduce aerosol properties locally.

\section{ACKNOWLEDGEMENTS}

This work was carried out as part of the PRIMES (contract $n$. I/017/11/0) and CLAM-PHYM (contract No. I/015/11/0) Projects, both funded by the Italian Space Agency (ASI).

\section{REFERENCES}

Bassani, C.; Cavalli, R.M.; Pignatti, S., 2010, Aerosol Optical Retrieval and Surface Reflectance from Airborne Remote Sensing Data over Land. SENSORS, , vol. 10, p. 6421-6438.

Bassani, C.; Cavalli, R.M.; Antonelli, P. , 2012, Influence of aerosol and surface reflectance variability on hyperspectral observed radiance. Atmos. Meas. Tech. 5, 1193-1203

Bey, I.; Jacob, D. J.; Yantosca, R. M.; Logan, J. A.; Field, B.; Fiore, A. M.; Li, Q.; Liu, H.; Mickley, L. J.; Schultz, M,.., 2001, Global modeling of tropospheric chemistry with assimilated meteorology: Model description and evaluation, J. Geophys. Res. ,106, 23,073-23,096.

Ben-Dor, E.; Kindel, B.; Goetz, A.F.H; 2004, Quality Assessment of Several Methods to Recover Surface Reflectance 
I using Synthetic Imaging Spectroscopy (IS) Data, Remote Sensing of Environment, 90, 389-404.

Conel, J. E., Green, R. O., Vane, G., Bruegge, C. J., \& Alley, R. E., 1987, AIS-2 radiometry and a comparison of methods for the recovery of ground reflectance. In G. Vane (Ed.), Proceedings of the 3rd Airborne Imaging Spectrometer Data Analysis Workshop JPL Publ., Vol. 87-30., pp. 18-47, Pasadena, CA: Jet Propulsion Laboratory.

D’Almeida, G.A; Koepke, P.; Shettle, E.P., 1991. Atmospheric aerosols: global climatology and radiative characteristics, A.DEEPAK Publishing, Hampton, Virginia, USA

Dubovik, O.; King, M. D. , 2000, A flexible inversion algorithm for retrieval of aerosol optical properties from Sun and sky radiance measurements, J. Geophys. Res., ,105, 20 673-20 696.

Gao, B. C.; Heidebrecht, K. B.; Goetz, A. F. H., 1993, Derivation of scaled surface reflectances from AVIRIS data. Remote Sensing of Environment, 44, 165-178.

Gao, B.-C; Montes, M.J.; Davis, C.O.; Goetz, A.F.H., 2009, Atmospheric correction algorithms for hyperspectral remote sensing data of land and ocean, Remote Sensing of Environment, 113, S17-S24.

Goetz, A.F.H; Vane, G.; Salomon, J. E.; Rock, B.N., 1985 , Imaging spectroscopy for Earth remote sensing, Science, 228, $1147-1153$

Guanter, L.; Alonso, L.; Moreno, J., 2005, A Method for the Surface Reflectance Retrieval From PROBA/CHRIS Data Over Land: Application to ESA SPARC Campaigns, IEEE Transactions on Geoscience and Remote Sensing, vol.43, no.12.

Guanter, L.; Estellès, V.; Moreno, J., 2007, Spectral calibration and atmospheric correction of ultra-fine spectral and spatial resolution remote sensing data. Application to CASI-1500 data. Remote Sens. Environ. 109, 54-65

Holben, B.N.; Eck, T.F.; Slutsker, I.; Tanré, D.; Buis, J.P. ; Setzer, A. ; Vermote, E. ; Reagan, J.A.; Kaufman, Y.; Nakajima, T.; Lavenu, F.; Jankowiak, I.; Smirnov, A., 1998, AERONET - A federated instrument network and data archive for aerosol characterization, Rem. Sens. Environ., 66, 1-16.

Kaufmann, Y.J.; Gobron, N.; Pinty, B.; Widlowski, J.-1; Verstraete, M.M., 2002, Relationship between surface reflectance in the visible and mid-IR used in MODIS aerosol algorithm - theory, Geophysical Research Letters,29.

Kaufman, Y.J.; Wald, A.; Remer, L.A.; Gao, B.C.; Li, R.R.; Flynn, L., 1997, The MODIS 2.1 umchannel-correlation with visible reflectance for use in remote sensing of aerosol. IEEE Trans. Geosci. Remote Sens., 35, 1286-1298.

Kokhanovsky A.A; Breon, F-M; Cacciari, A.; Carboni, E.; Diner, D.; Di Nicolantonio, W.; Grainger, RG.; Grey, W.M.F; Höller, R.; Lee, K-H; Li, Z.; North, P.R.J; Sayer, A.M; Thomas, G.E; von Hoyningen-Huene, W., 2007, Aerosol remote sensing over land: A comparison of satellite retrievals using different algorithms and instruments. Atmospheric Research, 85, 3, 372394.
Kokhanovsky, A.A. Aerosol optics: light absorption and scattering by particles in the atmosphere, 2008, Praxis Publishing Ltd, Chichester, UK,.

Kokhanovsky, A.A; Deuzé, J.L; Diner, D.J; Dubovik, O.; Ducos, F.; Emde, C.; Garay, M.J; Grainger, R.G; Heckel, A.; Herman, M.; Katsev, I.L; Keller, J.; Levy, R.; North, P.R.J; Prikhach, A.S; Rozanov, V.V; Sayer, A.M; Ota, Y.; Tanré, D.; Thomas, G.E; Zege, E. P., 2010, The inter-comparison of major satellite aerosol retrieval algorithms using simulated intensity and polarization characteristics of reflected light, Atmospheric Measurement Techniques, Vol.3, n 4, 909-932

Kotchenova, S.; Vermote, E.; Matarrese, R.; Klemm, F. Jr., 2006, Validation of a vector version of the 6 S radiative transfer code for atmospheric correction of satellite data. Part I: Path radiance, Applied Optics, 45, 6762-6774

Kotchenova, S.Y.; Vermote, E.F.; Levy, R.; Lyapustin, A.,2008, Radiative transfer codes for atmospheric correction and aerosol retrieval: Intercomparison study. Appl. Optics, 47, 2215-2226.

Kruse, F. A.; Raines, G. L.; Watson, K.; 1985, Analytical techniques for extracting geologic information from multichannel airborne spectroradiometer and airborne imaging spectrometer data, International Symposium on Remote Sensing of Environment, Fourth Thematic Conference, Remote Sensing for Exploration Geology, San Francisco, California.

Paronis, D.; Sykioti, O.; Kyparissis A., 2010, Effects of aerosols on narrowband indices and band depths from CHRIS/PROBA: Case study on a Phlomis fruticosa ecosystem, Proceedings of ESA Hyperspectral Worskhop, Frascati, Italy, 17-19 May 2010.

Richter, R., 1996, Atmospheric correction of DAIS hyperspectral image data. Computers \& Geosciences, 22, 785-793.

Roberts, D. A., Yamaguchi, Y.; Lyon, R.,1986, Comparison of various techniques for calibration of AIS data. In G. Vane, \& A. F. H. Goetz (Eds.), Proceedings of the 2nd Airborne Imaging Spectrometer Data Analysis Workshop JPL Publication, Vol. 86-35., pp. 21-30.

Vermote, E. F. ; Tanré, D.; Deuzé, J. L.; Herman, M.; Morcrette, J.-J., 1997b, Second simulation of the satellite signal in the solar spectrum, 6s: an overview, IEEE Transactions on Geoscience and Remote Sensing, vol. 35, no. 3, pp. 675-686.

Vermote, E.F.; Tanre, D.; Deuze, J.L.; Herman M.; Morcrette J.J, 2006, Second simulation of the satellite signal in the solar spectrum - Vector (6SV): http://6s.ltdri.org, 6S User Guide Version 3,

Vermote, E. F.; El Saleous, N. Z.; Justice, C. O.; Kaufman, Y. J.; Privette, J. L.; Remer, L.; Roger, J. C.; Tanre, D. , 1997, Atmospheric correction of visible to middle-infrared EOSMODIS data over land surfaces: background, operational algorithm and validation. Journal of Geophysical ResearchAtmosphere, 102(D14), 17131 - 17141. 